\title{
Navigating a Pandemic: A Qualitative Study of Knowledge, Sources of Information, and COVID-19-Related Precautions Taken by HBCU Students
}

\author{
Jeannette Wade ${ }^{1}$ (1) - Stephanie Teixeira Poit ${ }^{1} \cdot$ Anna Lee $^{1} \cdot$ Sally Ryman ${ }^{1} \cdot$ Dextiny McCain $^{1} \cdot$ Christopher Doss $^{1}$. \\ Smriti Shrestha ${ }^{1} \cdot$ Adrienne Aiken Morgan $^{1,2}$
}

Received: 9 August 2021 / Revised: 7 December 2021 / Accepted: 9 December 2021 / Published online: 15 January 2022

(c) W. Montague Cobb-NMA Health Institute 2021

\begin{abstract}
The coronavirus (COVID-19) has spread quickly across the nation with a disproportionate impact on Black Americans. Many college-aged students receive their COVID-19-related information through social media and television even though research suggests that social media sources are more likely to be incorrect. Some students report trusting these sources over government sources such as the CDC and WHO. The purpose of this study was to understand Historically Black College and University (HBCU) students' COVID-19 knowledge, sources of information, and planned precautions. There were 21 in-depth interviews conducted with students attending a large southern HBCU during Spring 2020. Themes regarding knowledge included the following: it is a flu-like condition, it has international roots, there is inaccurate and changing information, and it is a pandemic. Themes regarding sources included: the news, US government and related officials, social media, interactions with family, and other social interactions. Themes regarding severity included the following: statistics, a distrust for hospital reporting, a belief that COVID-19 deaths were conflated with baseline health, peer influence, and familial influence. Themes regarding precautions included the following: proper mask use, hand washing/ sanitizing, avoiding large crowds/ small crowds only, physical distancing, COVID-19 testing/symptom monitoring, and COVID-19 vaccination.
\end{abstract}

Keywords COVID-19 $\cdot$ Race $\cdot$ Social determinants of health $\cdot$ Coronavirus $\cdot$ Information-seeking behaviors $\cdot$ Health inequalities

\section{Introduction}

Research related to the coronavirus (specifically, COVID19) is revealing that even though most, if not all, people have heard about the virus, the sources and format of information delivery also differs across sociodemographic categories. Many college-aged students receive their COVID-19-related information via social media and television, while others receive information through healthcare workers, community leaders, and/or news media [1]. According to the Pew Research Center, $77 \%$ of Black emerging adults ages 18-29

Jeannette Wade

jmwade1@ncat.edu

1 North Carolina Agricultural and Technical State University, Greensboro, NC, USA

2 Department of Psychiatry, School of Medicine, University of North Carolina at Chapel Hill, Chapel Hill, NC, USA use social media [2]. Research has also shown that Black Americans and other racial and ethnic minority groups are more likely to post COVID-19-related content than their White counterparts [3]. Although studies show that information received from social media sources are more likely to be incorrect, some students tend to trust these sources over government entities such as the CDC and World Health Organization (WHO) [2] Because many Americans receive information from different sources, misconceptions and misinformation regarding COVID-19 are likely. Whereas most young people know the main symptoms of COVID19 , how it is transmitted (e.g., direct contact with infected people), and how to prevent the spread (e.g., wearing masks, handwashing, and sanitizing, etc.), some students believe the virus can be transmitted through contaminated food [4]. In addition, some individuals believe masks are protective against COVID-19, but only infected persons should wear them to reduce transmission [5]. 
COVID-19 has spread quickly across the nation and has had a differential impact across sociodemographic subgroups [6]. Black Americans have been disproportionately impacted by COVID-19, representing $15.8 \%$ of virus-related deaths US Centers for Disease Control (CDC) [7] and only 13.4\% of the US population [8]. Black Americans also have a hospitalization rate that is $2.8 \times$ the rate of their White American counterparts. Young adults have also been diagnosed with COVID-19 at disproportionate rates. While $95.5 \%$ of COVID-19-related deaths in the USA involved individuals 55 and over, $22.7 \%$ (over 4 million) of those infected were between ages 18 and 29 [7]. Given the prevalence rates of hospitalizations and death, and disparities by race and age, it is vital to understand where young Black Americans get insights about the COVID-19 virus, related precautions, and how they take heed to any suggested behavioral changes. In the following sections, we review what is known about racial differences in virus knowledge and illness-related precautions.

\section{Background}

\section{Race, Knowledge, and Illness-Related Precautions}

Literature on youth's attitudes toward previous viral outbreaks (flu, H1N1, and Zika virus) shows that knowledge of the virus, perceived susceptibility and severity, access to accurate information, and influence from friends, family, and healthcare providers are important factors for vaccine uptake [9-11]. While most studies have predominantly White samples, studies that do examine racial and ethnic minorities find that Black Americans have lower vaccination rates than their White American counterparts for the flu, HPV, and pneumonia, with distrust as a reason against vaccination [12-14].

Studies have found important group specific differences in COVID-19 knowledge. Individuals with higher levels of education had significantly higher COVID-19 knowledge index scores than their less educated counterparts [15]. Additionally, in Kecojevic and colleagues' [16] study of college students, generally, there was a very good understanding of COVID-19 transmission modes and common symptoms. College students also generally agreed with using social distancing measures, and they mostly used official sources to learn about COVID-19, such as the government and medical professionals. Interestingly, even though $23 \%$ of college students reported trusting non-official sources of information, such as social media, family, and friends, about $46 \%$ of them reported using these unofficial sources to learn about COVID-19.

There were also important differences across domains of knowledge for individuals of different races and ethnicities.
Specifically, COVID-19 knowledge index scores were lower for non-Hispanic Black individuals than non-Hispanic white individuals for the following knowledge domains: severity and mortality, transmission, vaccines and treatment, and misinformation [16]. Studies have also found that Black individuals reported being less worried about COVID-19 and being less likely to think that they were susceptible to becoming infected with COVID-19 than other subgroups $[17,18]$. Furthermore, Black individuals were also less likely to report being prepared for COVID-19 or knowing how to prevent getting infected with COVID-19 compared to other subgroups [15, 18]. This latter finding was supported by a study using the Chicago COVID-19 Comorbidities survey, which found that Black adults and men were less likely to report practicing social distancing than White adults and women respectively, when controlling for all other factors [19].

In a qualitative study of Black women in the USA, Chandler, and colleagues [20] found that $58 \%$ of participants obtained information about COVID-19 from social media platforms or televised news sources. About one third of Black women sampled also received information about COVID-19 from other unofficial sources, such as email updates, texts, family, or friends. In comparison to the results presented above, this study suggests that Black individuals may use unofficial sources of information at a higher rate than other subgroups, a potential cost associated with governmental distrust in this community. Seventy nine percent of Black respondents also avoided official sources of information because they found it to be confusing [20]. Scholars have cautioned against the use of non-scientific or unclear sources of information for learning about COVID19; they also found that COVID-19 information on official government websites tended to be written at a high school or college reading level, not a 5-7th grade level as widely recommended [21]. Thus, health literacy seems to be an important predictor of understanding COVID-19 information presented. Indeed, studies found that individuals with low health literacy were less likely to think they were susceptible to COVID-19 [17] and less likely to engage in preventive practices, such as stopping leisure or group activities or preemptively obtaining needed prescription medications [20].

\section{Critical Race Theory, Structural Racism, and Health}

It is established that Black Americans have worse outcomes as it relates to COVID-19. Given the racial inequities laid bare by the COVID-19 pandemic, critical race theorists would assert that scientists should center racially marginalized groups in the study of social phenomena [22]. Specifically, they should acknowledge the social construction of race, racism, and their impact on lived experiences. So, in 
this case, to understand and address this health equity concern, we must consider psychosocial aspects of the Black experience in America and how they may or may not impact access to virus knowledge and related precautions.

Information regarding preventing and contracting COVID-19, however, has been problematic from the beginning, especially when it comes to the Black community. According to Cultivation Theory, the more viewers are exposed to media images, the more susceptible they are in believing the images and the messages are valid and real [23]. This is particularly concerning for HBCU students, who Kim et al. [24] reported spend $7 \mathrm{~h}$ per day on social media, 3 of which are for leisure. This means Black emerging adults had greater exposure to contradictory information coming from the government, a lack of a nationwide mandated response, and even CDC guidelines changing over time. Additionally, there have been false reports on social media that Blacks were immune to the virus along with other factually inaccurate updates [25].

Public opinion polls highlight a racial disparity in COVID-19 vaccine hesitancy by race, with $40 \%$ of Black Americans planning not to get a vaccine compared to $16 \%$ of white Americans [26]. This racial disparity in COVID19 vaccine hesitancy relates to mistrust in the medical system among Black Americans. Trust is critical in promoting information-seeking behavior about COVID-19 vaccines. Yet, Black Americans have experienced medical racism at the hands of the health department and US government for centuries (See: Alabama Fistula Study, Heat Stroke Study, Tuskegee Experiment, and Measles Vaccine Trails), which fosters a sense of distrust in government and medicine $[27,28]$ and impacts how messages about COVID-19 are received. Mistrust is also impacted by the broader context of race relations in America, systemic racism that has been institutionalized in the USA, and everyday racism and disrespect that Black Americans experience [29, 30]. Recognizing that many Black Americans consciously decide against vaccination, some activists argue that vaccine mandates discriminate against Black Americans by disproportionately impacting and limiting their participation in society [31].

As a population that is distinctly vulnerable to the virus, it is top priority to understand Black Americans' sources of information to create culturally sound approaches to prevention and intervention during pandemics such as COVID-19. We do so by using a sample of Historically Black Colleges and Universities (HBCU) students since emerging adults (diagnosis) and Black Americans (hospitalizations and mortality) have been shown to be among the highest risk Americans. Our guiding research questions for this study were (1) What do HBCU students know about COVID19? (2) What are their sources of information? And (3) what precautions are they taking to slow the spread of the virus? This study will add to the scientific understanding of COVID-19-related knowledge, information sources, and related precautions taken by HBCU students using results of in-depth interviews.

\section{Methods}

Our team used flyer distribution to secure a sample of $\mathrm{HBCU}$ students to uncover their concerns about COVID-19 and remote learning via quantitative surveys. The research team circulated flyers on social media and through various listservs from the department, college, and university levels. We solicited interviewees via a poll included in the quantitative survey. Respondents were informed of the opportunity to participate in in-depth interviews and the potential to secure a $\$ 50$ gift card as an incentive for their time. Interviews lasted 40-60 min and covered topics ranging from COVID-19 knowledge and related precautions to barriers and promoters of school success. Inclusion criteria included being a student enrolled during the Spring 2020 semester and thus impacted by the campus shutdown. This study received approval from the Institutional Review Board at North Carolina A\&T State University (IRB \#19-0214).

\section{Data Collection}

Data collection utilized interview guides developed by three principal investigators (PIs) on the research team. The qualitative component of this study was explanatory in nature [32]. This allowed us to augment and contextualize quantitative findings on COVID-19-related knowledge and vaccinerelated intentions. The in-depth interviews also allowed us to better understand a novel topic, which, in this case, was the conceptualization of COVID-19 among HBCU students [33]. Given the disproportionate impact of COVID-19 on Black Americans and young adults, it is vital to understand the sources of information and actions taken by this group. Due to CDC and campus COVID-19 guidelines, the research team conducted and recorded interviews using Zoom software. The findings reported here come from 21 in-depth interviews from students who completed the quantitative survey and consented to follow-up interview. More information on the respondents is detailed in Table 1.

Interviews were conducted during Summer and Fall 2020. Respondents provided online consent via Qualtrics software.

\section{Data Analysis}

Audio files from in depth interviews were transcribed using Zoom's transcription service. Prior to the coding process, interviewers verified and de-identified the transcripts. Principal investigators developed the codebook, definitions, and examples of emerging themes. Research assistants 
Table 1 Descriptive statistics for interview participants

\begin{tabular}{ll}
\hline Full sample $(N=21)$ & Number \\
\hline Age & \\
$18-19$ & 6 \\
$20-21$ & 6 \\
$22-24$ & 4 \\
$25+$ & 5 \\
Sex & \\
M & 3 \\
F & 18 \\
Race/ethnicity & \\
Black American & 18 \\
Black Foreign Born & 1 \\
White American & 2 \\
K-12 urbanicity & \\
Urban & 4 \\
Suburban & 12 \\
Rural & 5 \\
Virtual learning location & \\
On campus & 3 \\
Nontraditional student-stayed home & \\
Off-campus housing & \\
Return home & 4 \\
\hline
\end{tabular}

assisted with analysis using established codes. New themes that emerged during data analysis were reconciled by the team as a unit. We feel confident that we reached both data and meaning saturation through our data analysis process. According to Hennink et al. [34], code saturation refers to the research team uncovering every theme present in the data. Code saturation is established with around nine interviews. Meaning saturation, however, refers to a research team uncovering the full range of each code's definition. So, for example, if we see "social media" as an emergent theme for sources of information, meaning saturation would mean identifying references to "social media" varying from posts by peers to CDC reports shared via newsfeeds. Meaning saturation is established with 16-24 and our sample of 21 falls within that range. Additionally, Hennink et al. [34] also noted that smaller samples are sufficient to reach saturation in studies of homogeneous populations.

\section{Results}

Interviewees were asked questions about their knowledge regarding COVID-19 and to understand precautions they were taking to slow the spread of the virus. Major themes, codes, and frequencies are displayed in Table 2.
Participants' answers to, "So, what do you know about COVID-19 in terms of what it is and how it started?" were summarized in the following themes: it is a flu-like condition, it has international roots, there is inaccurate and changing information, and it is a pandemic. Sample quotations follow.

\section{Flu-Like Condition}

Several students described COVID-19 as a minor sickness akin to the common flu. This was a common misconception early in the pandemic. The idea that COVID-19 was akin to the flu originated from a televised presidential press conference in 2020. Because Black Americans watch television and use social media at greater rates than their White counterparts, they are easier to access and impact with messages that are televised then viral online [35]. Responses ranged from complete minimization, "it's kind of like the flu. But at the same time, it's not because its asymptomatic," to progressively experiencing feelings of concern.

“And initially, I know that they didn't think it was as deadly as it was, until probably the beginning of March is when they started to shut things down and realize that it is a little more deadly than the flu."

\section{International Roots}

Students also described COVID-19 as an international virus that spread to the USA. The fact that COVID-19 emerged from China is non-contested information. The potentially social aspect of this theme is the focus on the geographical location of the first case. As with the idea that COVID-19 is a flu-like virus, the fact that it originated in China was also the focus of televised presidential press conferences [36].

"From the little bit that I do understand, I know that it started in China. It spread quickly through travel. People coming back and forth from China to America."

\section{Inaccurate and Changing Information}

Some students expressed frustrations around the changing nature of information. They felt there was no consensus on what COVID-19 was or how to navigate it. Given the abundance of sources, lack of consensus between the white house and $\mathrm{CDC}$, and general panic around the pandemic, many Americans likely experienced feelings of frustration. When you consider the tumultuous relationship between Black America and the field of health care, it is likely more frustrating sifting through mixed messages from an institution that is already stigmatized was not trusted. 
Table 2 COVID-19 knowledge and precaution codes, themes, and frequency distributions

\begin{tabular}{|c|c|c|c|}
\hline Question & Codes & Frequency & Example quotes \\
\hline \multirow{4}{*}{$\begin{array}{l}\text { So, what do you know about COVID-19 in } \\
\text { terms of what it is and how it started? }\end{array}$} & Flu-like condition & 9 & \multirow{4}{*}{$\begin{array}{l}\text { "... when it originally came out, I heard that it } \\
\text { came from China, and it's a virus. That basi- } \\
\text { cally affects the body." }\end{array}$} \\
\hline & International roots & 14 & \\
\hline & Inaccurate/changing information & 7 & \\
\hline & Pandemic & 3 & \\
\hline \multirow{6}{*}{$\begin{array}{l}\text { Can you tell me about your sources of informa- } \\
\text { tion on COVID-19? }\end{array}$} & News & 9 & \multirow{6}{*}{$\begin{array}{l}\text { "Well, I get most of my news information from } \\
\text { Twitter." }\end{array}$} \\
\hline & US government & 5 & \\
\hline & Online sources & $13^{*}$ & \\
\hline & Classes & 3 & \\
\hline & Interactions with family & 3 & \\
\hline & Place of employment & 2 & \\
\hline \multirow{4}{*}{$\begin{array}{l}\text { Let's talk about you, what are your feelings } \\
\text { about the severity of the virus? }\end{array}$} & Like the flu & 6 & \multirow{4}{*}{$\begin{array}{l}\text { "Um, I think, it is very severe especially to those } \\
\text { that are more vulnerable." }\end{array}$} \\
\hline & Serious but avoidable & 3 & \\
\hline & Very serious & 12 & \\
\hline & Other & 2 & \\
\hline \multirow[t]{5}{*}{ How did you come to feel that way? } & Statistics & 5 & \multirow{5}{*}{$\begin{array}{l}\text { "And so, I didn't feel comfortable putting so } \\
\text { much trust and other people and their deci- } \\
\text { sions. I knew I can control my environment, } \\
\text { which is my mom and I hear as much as } \\
\text { possible." }\end{array}$} \\
\hline & Distrust hospital reporting & 3 & \\
\hline & COVID-19 vs. baseline health & 2 & \\
\hline & Influenced by friends & 4 & \\
\hline & Influenced by family & 5 & \\
\hline \multirow{6}{*}{$\begin{array}{l}\text { Do you take any precautions to avoid COVID- } \\
19 ? \text { If so, what? If not, why is that? }\end{array}$} & Proper mask use & 15 & \multirow[t]{6}{*}{ "Yes, for the most part I stay in the house." } \\
\hline & Hand washing/ sanitizing & 11 & \\
\hline & Avoiding large crowds & 11 & \\
\hline & Physical distancing & 10 & \\
\hline & Covid-19 testing & 4 & \\
\hline & Covid-19 vaccination & 6 & \\
\hline
\end{tabular}

*11 students referenced social media, 2 students referenced Google

"I know they say it came from the food or something. Some people said it was bat spit up or I think it can be airborne too."

\section{Pandemic}

COVID-19 was also described as a pandemic. Students who felt this way saw it as more severe than the flu. They talked about it being serious enough to cause the country to shut down. The quote from below comes from a student who was swayed by a cautionary article.

"It was actually back in I think like December, January, and it was an article that I read about America not being ready for a global pandemic and things."

Interviewees were asked about their sources of information to better understand contributors to their diverse perspectives on the virus. Responses to "Can you tell me about your sources of information on Covid-19?" were summarized in the following codes: the news, us government, online sources, interactions with family, interactions with friends, classes, and their place of employment. Example quotes are below.

\section{News}

The first theme that emerged when we analyzed the question on sources was the news. This varied from local news to national news outlets. Given the wide range of reliability, bias, and use of science in news casting, students who trust the news may or may not consume factual health-related information about the pandemic.

\section{US Government}

The second theme that emerged when we analyzed the question on sources was the government and related officials. This included references to former Presidents Obama and Trump and their views and opinions and precautionary actions and the severity of the virus. There were also references to the CDC that we coded in this theme, "I prefer the $\mathrm{CDC}$, because that's pretty much what they're known for. 
They're known for disease control and how we're supposed to handle it."

\section{Online Sources}

The third theme that emerged when we analyzed the question on sources was online sources. Twitter seemed to be a widely trusted source for the participants with 11 mentioning social sites like Twitter and YouTube and 2 mentioning search engines like Google. Twitter is perhaps less reliable than the news media as it contains an even broader range of data on COVID-19. One respondent detailed how social media portrayed the virus as a joke and framed it as a "bat virus."

\section{Interactions with Family}

The fourth theme that emerged when we analyzed the question on sources was interactions with family. Students generally described their parents as cautious during the pandemic and proponents of adhering to CDC recommendations. Interactions with family as a source of vital information have become a valued custom in the Black community. Popular news outlets have been historically segregated, so Black Americans use words of mouth as a key form of information sharing [37].

\section{Interactions with Friends}

The fourth theme that emerged was interactions with friends. Friends are conceptualized here as non-familial individuals who have platonic, intimate relationships. Students discussed being around friends when the news broke and reflected on their shared reactions. Students also discussed talking to friends who worked in the medical field. They put a great deal of confidence in those friends first had experiences.

\section{Classes}

Fifth, the classroom emerged as a source of information on COVID-19. In their study of 5800 college students, Head et al. [38] found that $73 \%$ of students received news updates during conversations with their professors and over $40 \%$ selected news outlets based on recommendations form faculty. The abundance of panic and concern around the pandemic meant many classroom discussions had to shift from discipline specific to current events. One student noted "all of my teachers switch their lectures to center it (the virus)." Students talked about classroom discussions that ranged from venting, to processing, to data analysis around COVID19 and its impact on the globe.

\section{Place of Employment}

The sixth theme that emerged was place of employment. Students who reported getting virus-related updates at work exclusively came from the medical field. They mentioned serving patients who contracted the virus and receiving updates on the pandemic from coworkers and members of their leadership team.

\section{Other Social Interactions}

Other sources of information included social interactions outside the family and social media. The example below shows a student learning about the coronavirus at a tournament.

"And then, you know, like the next day our coach gets the call that the tournament's cancelled... we have to go back home."

Next, our research team read the following prompt to participants, "Let's talk about you, what are your feelings about the severity of the virus?" Interviewee responses can be summarized by three main themes: the virus is like the flu, it is serious, but avoidable, and very serious. One dissimilar response was coded as other.

\section{Like the Flu}

The first emergent theme came from students who described the coronavirus as like the flu, manageable for some and challenging for others. The idea that COVID19 is like the flu and is not a major concern for emerging adults speaks to a developmental concern known as a sense of invulnerability [39]. Specifically, individuals ages 18-25 (1) are more likely to engage in health risk behavior and (2) fail to connect today's behaviors with tomorrow's consequences $[40,41]$.

"But I feel like, like the flu, like most people who are dying are older people or people already with things are wrong with them. So, it makes them more high risk."

\section{Serious, but Avoidable}

In terms of severity, there was a group of students whose responses fell between like the flu and very serious. These students spoke to the seriousness of the virus while also discussing ways to avoid contracting it. One respondent spoke hopefully about the vaccine and the development of a cure. Another student claimed that although COVID-19 is serious, 
"a lot of it is mainly overhyped. Me personally, I've never seen or known people who died or whatever."

\section{Very Serious}

The third emergent theme came from students who thought the virus was very serious and that significant actions were needed to slow the spread. Some students worked in health care-related fields and talked about patients they had seen suffering from the virus, other students talked about loved ones impacted by the virus. Other students even mentioned the death toll which is represented in the quote below.

"I think that it's very severe especially how I see that America is pretty much the only country that didn't take that many precautions. And our death toll is growing daily, and you hear on the news how like, there's hospital shortages and all that. I feel like it's very severe and we're still not taking it serious."

\section{Other}

The first theme coded as other came from a student respondent who thought the virus was not too severe and thus, it was inappropriate to shut down the country,

"Eventually, at some point, everybody is going to have to like be exposed to it, unless we just completely lock down and shut down the entire world forever, but obviously I don't think that's going to happen."

This perspective is likely linked to misinformation coming from nonscientific news reports and social media posts. In the case of HBCU students, this could also be an example of a social psychological tactic to avoid discussing the stark differences between homelife and campus life. Stayat-home orders for many Black American college students meant leaving the safety net of campus and returning to issues around access to food, safe places to exercise, and a peaceful space to complete schoolwork [42].

Next, we asked the respondents, "How did you come to feel that way?" in terms of their beliefs around the severity of COVID-19. Their perspectives were shaped by statistics, a distrust for hospital reporting, a belief that data around COVID-19 and related deaths was conflated with baseline health, peer influence, and familial influence.

\section{Statistics}

First, our analysis showed that five of our HBCU students drew a conclusion about COVID-19 based on statistics. Students who referred to statistics saw numerical data, science, and growing mortality rates, as useful tools in terms of understanding the prevalence and impact of the virus.
Although our culture values the use of numerical data in understanding social phenomena, the quote below shows how it can be alarming and not always harmful when presented without context. Additionally, focusing on incidence rates is less effective in terms of promoting change in racial groups like African Americans [43].

"I'm looking at the news and seeing the death rates, especially amongst African Americans... it's just very confusing especially hearing from different sources."

\section{Distrust Hospital Reporting}

Other students, however, were less trusting of statistics, particularly those from hospitals. These respondents felt it was in the hospital's best financial interest to overstate COVID19 diagnoses and deaths to secure government funding. The quote below comes a student who clearly believes the medical field is not trustworthy and operates by prioritizing financial gain over patient care. This perspective is likely rooted in past trauma and stories shared by cautious (or previously victimized) friends and family.

"Like I have seen people die from heart disease or, oh, simply old age.... lot of hospitals, the more cases they have... that's how they get more equipment."

\section{Believe COVID-19 is Conflated with Baseline Health}

Similarly, another group of students believed hospital data was faulty and was due to conflating COVID-19 outcomes with pre-existing conditions also referred to as comorbidities. These students claimed COVID-19 outcomes were overstated and easily conflated with poor baseline health.

"You know they have cancer, but then they get COVID-19, and COVID-19 makes it worse."

\section{Influenced by Friends and Family}

Finally, students' perspectives on the severity of COVID19 were influenced by friends and family. Generally, those whose family and friends had been negatively impacted by COVID-19 considered the virus to be very severe. Responses mentioned seeing loved ones following all the guidelines and still contracting the virus and even loss as highlighted in the quote below.

"I have had friends passed away from it recently. Well last week, my daughter's boyfriend, his younger sister lost her three-month-old baby too so."

Finally, after gathering data on COVID-19-related knowledge and sources of information, the research team asked interviewees about any precautions they planned to take to 
slow the spread of the virus. Responses were summarized by the following themes proper mask use, handwashing, avoiding large crowds, physical distancing, symptom monitoring, and getting vaccinated.

\section{Proper Mask Use}

First, most of our respondents reported that they would help slow the spread of COVID-19 by engaging in proper mask use. Although a divisive topic in the USA, mask wearing is the number one CDC recommendation for individuals leaving the house during the pandemic. For Black Americans in particular, wearing a mask allows them to slow the spread through personal actions, not taking a vaccine which is widely distrusted in their community [44].

"Yes, so I wear a mask every single time I go out. Occasionally, often in the beginning, I also wear gloves"

\section{Hand Washing/Sanitizing}

Second, students claimed they have been, and will continue to, wash and sanitize their hands and items they touch. Like mask wearing, hand washing and sanitizing are autonomous ways HBCU students can protect their health without using formal medical interventions. Additionally, adhering to this precaution may have been less challenging for our population as they are more engaged in hygiene practices on a regular basis. Anderson and colleagues [45] conducted an observational study of handwashing in campus restrooms and found that $76.3 \%$ of Black students washed their hands with soap, while a smaller $57.1 \%$ of Whites and $49.6 \%$ of Asian students did.

"Hand sanitizer.... But especially at *store $\mathrm{X} *$ because you got to think people touch stuff and put it back. You touched on this earlier, they touch the cereal. The doors. The grocery carts"

\section{Avoiding Large Crowds/Small Crowds Only}

A third way students planned to take precautions was to avoid large crowds. Students did this by staying home,

"Yes, for the most part I stay in the house unless I have to go somewhere and when I do go places like the store, or any outings, I wear a mask."

and finding alternative ways to connect with their loved ones. This strategy came with noted distress. Respondents talked about missing loved ones and having to make difficult decisions around who to socialize with.
"I don't travel frequently. I don't really see my family members or my extended family members. We meet on zoom a lot."

\section{Physical Distancing}

For those who were unable to avoid large crowds, they reported a fourth option, which was engaging in physical or social distancing. The inability to adhere to stay-at-home orders represents a lack of privilege and health-related autonomy that was laid bare by the pandemic. The CDC [7] lists overrepresentation in essential work as a social determinant of COVID-19 diagnoses for Black Americans.

"As far as like working in healthcare. I try my best not to go around my family, especially when I had to work with COVID-19 patients. I did not go around my family, but if I do feel a little under the weather, then I normally quarantine myself at home"

\section{COVID-19 Testing/Symptom Monitoring}

Fifth, students discussed symptom monitoring and COVID19 testing. Students talked about how daunting travel can be with all the testing requirements and how they disliked the nose swabs used in early COVID-19 test kits. The student below describes how vital testing is given the prevalence of asymptomatic carriers.

"I think that people should get tested whether have any symptoms or not because I do believe that there is a such thing as carriers. I also believe that they shouldn't do any more of the, you know, the temperature checks, because carriers... asking them, you know, 'how do you feel, have you had a fever, how you have been' I just feel like it was not accurate, due to the people that are carriers and don't have some of them."

\section{COVID-19 Vaccination}

A sixth precautionary action that respondents mentioned was COVID-19 vaccination. Students compared the COVID-19 vaccine to the flu vaccine and wondered if it would similarly only provide immunity from certain strains of the virus. They also compared the two vaccines in terms of potential for side effects and sickness. Despite seeing the value in the vaccine, the respondent below mentioned trepidations about being among the first to try the new medication.

"I believe that people should get the vaccine. You know, I believe that we should get vaccinated, but I do not want to be one of the first ones." 


\section{Discussion}

Our findings add to the literature by providing perspectives of HBCU students' knowledge, sources of information, and planned precautions regarding COVID-19. According to medical sociologists, Williams and Sternthal [46], the impact of racism and cultural differences is largely ignored in studies of health disparities. Additionally, public health scholar Lisa Bowleg [47] argued that individuals who have marginalized identities should be at the center of health research since it is well established that oppression is a predictor of poor health. This means, rather than situating Black college students as a comparison group (alongside other college students), we situate them as the point of interest [48].

Regarding knowledge, participants expressed that early information insinuated that COVID-19 was a minor sickness like the flu; however, this was dispelled as the country began to shut down and the deadly consequences of infection were more well-known [49]. Also, as found in other studies, students indicated that the origin of the virus was attributed to China and that it spread to the USA from there, but students did not endorse conspiracy theories such as the virus was human engineered [50]. The frustration of changing information regarding the virus reported by participants aligns with concerns of citizens across the USA [51].

Participants indicated that the news, the government, social media, family, and interactions with others were sources of information regarding the virus. Local and national news outlets, government-related channels including the former President Obama and agencies such as the CDC were viewed as trusted sources. Naeem and Bhatti [52] suggested that COVID-19 has spurred a massive "infodemic" in which the public has been bombarded with large amounts of information, much of which is not scientifically correct. Some participants indicated that they used social media as an alternative to news despite evidence that misinformation about the pandemic occurs frequently on these platforms and can be a source of health risk $[53,54]$. Another key source of information revealed in our study was family, specifically parents. Most of the research on COVID-19 and parents has focused on those with young children. This study indicates that parents along with other social interactions with trusted individuals influenced their emerging adult children's attitudes and perceptions about COVID-19.

Regarding severity of the virus, responses ranged from the nationwide shut down was unnecessary to the virus is very serious. This finding aligns with a study that indicated that many US adults in March 2020 to April 2020 severely underestimated their fatality risk from COVID-19 and the virus was no more serious than the flu [55]. Participants based perceptions of severity on statistics; however, they also reported distrust of hospital reporting and the belief that data were being conflated with pre-existing conditions. Perceptions of severity were also based on first-hand accounts from family and friends that had been negatively impacted by the virus which is aligned with previous research $[56,57]$.

Finally, participants indicated plans to adhere to precautions including engaging in proper mask use, washing, and sanitizing hand, avoiding large crowds, and physical distancing. In a study examining whether mask usage, social distancing, handwashing, and stocking up on food/ supplies were associated with COVID-19 vaccine intentions, it was found that those with positive vaccine intentions were more likely to engage in precautionary behaviors [58]. In a national survey by the National Opinion Research Center (NORC) completed in May 2020, Black and Hispanic respondents, respondents who were females, younger, and those who were more politically conservative were significantly less likely to report intending to be vaccinated. Overall, participants viewed testing as important and vital to slowing the spread of the COVID-19 virus. To return to Critical Race Theory, our results support the notion that we must consider psychosocial aspects of race in studies of social phenomena like the COIVD-19 pandemic [59].

\begin{tabular}{|c|c|c|c|}
\hline $\begin{array}{l}\text { Problem: Race Specific } \\
\text { Health Disparity }\end{array}$ & $\begin{array}{c}\text { Theoretical Framework: } \\
\text { Critical Race Theory - } \\
\text { Delgado and Stefancic (2001) }\end{array}$ & $\begin{array}{l}\text { Approach: Apply CRT to } \\
\text { Covid Knowledge and } \\
\text { Precautions }\end{array}$ & $\begin{array}{l}\text { Findings: Identified } \\
\text { Precautions Take }\end{array}$ \\
\hline $\begin{array}{l}\text { - Covid-19 Diagnosis Rates } \\
\text { - Known Mechanism: Virus } \\
\text { Knowledge and Precautions } \\
\text { Taken }\end{array}$ & $\begin{array}{l}\text { - Center marginalized groups } \\
\text { in the study of social } \\
\text { phenomena } \\
\text { Acknowledge the social } \\
\text { construction of race, racism, } \\
\text { and their impact on lived } \\
\text { experiences }\end{array}$ & $\begin{array}{l}\text { - Use qualitative interviews to } \\
\text { contextualize race related } \\
\text { health disparities }\end{array}$ & $\begin{array}{l}\text { - Proper mask use } \\
\text { - Hand washing/ sanitizing } \\
\text { - Avoiding large crowds/Smal } \\
\text { crowds only } \\
\text { - Physical distancing } \\
\text { - Covid-19 Testing } \\
\text { - Symptom monitoring } \\
\text { - Covid-19 vaccination }\end{array}$ \\
\hline
\end{tabular}

Fig. 1 Model displaying the path of our findings from trends in racial disparities to context using a critical race lens 
Figure 1 displays the path of our findings from trends in racial disparities to context using a critical race lens (see Fig. 1).

\section{Limitations}

An overarching limitation is the greater likelihood of bias that has been associated with qualitative research. Specifically, the design and implementation of qualitative research lends the approach to higher susceptibility to positionality bias, analytical bias, and social desirability bias [32]. To address positionality, our research team created checks and balances by using a racial, ethnic, and disciplinary diverse team of scholars to conduct the data analysis. In addition, analytical bias was mitigated through the team's inclusion of three experienced qualitative researchers and two graduate student assistants. To minimize social desirability bias, participants were assured their responses would be deidentified to maintain confidentiality. Study participants could provide outside evidence of their views, not just their own personal experiences.

Our study is also limited by the makeup of the sample, which had substantially more women than men. We acknowledge that medical racism and historical instances of racism in science make it challenging to recruit Black men for health-related research. The stay-at-home orders that were in place during data collection stopped us from engaging in best practices like personal interactions, sharing meals together, adding trusted community members to the study team, and recruiting from trusted locations like barber shops [60,61]. We do not believe this limitation devalues our qualitative data as the goal of our study was to contextualize quantitative trends, so we sought after composite data (among HBCU students), not comparative data (by sex).

\section{Conclusion and Future Directions}

In conclusion, findings of this study make a meaningful contribution to the literature by providing data on HBCU students' knowledge, information sources, and perspectives on precautions associated with the COVID-19 pandemic. Considering the disproportionate impact of the virus on Black communities, it is critical to understand attitudes and perceptions among Black individuals. These data can be used to inform health interventions on campuses and other spaces occupied by Black Americans and young adults. Other health issues like HIV and diabetes have been prioritized by public health initiatives and the COVID-19 virus and vaccinations should be at the forefront as well. Universities should also consider implementing programs to aid in the navigation of social media for information gathering, considering the high probability of misinformation. The current generations and those to follow will lean on the internet for its immediacy, so it is vital that they know which sites are trustworthy and how to read and interpret basic statistics.

Acknowledgements We would like to acknowledge Dr. Moige Ongeri and ETR services for their contribution to the success of this project.

Funding This work was supported by the National Science Foundation under RAPID Award \#2033926 (PI: Aiken-Morgan). Any opinions, findings, conclusions, and/or recommendations are those of the investigators and do not necessarily reflect the views of the Foundation.

\section{Data Availability NA}

Code Availability Via email from the corresponding author.

We would like to acknowledge Dr. Moige Ongeri and ETR services for their contribution to the success of this project.

\section{Declarations}

Ethics Approval and Consent to Participate All procedures performed in studies involving human participants were in accordance with the ethical standards of the institutional and/or national research committee and with the 1964 Helsinki declaration and its later amendments or comparable ethical standards.

Competing Interests (include appropriate disclosures). The research team received a grant from the National Science Foundation. There are no other potential conflicts to report.

- NC A\&T SU IRB Notice-19-0214.

Informed Consent Informed consent was obtained from all individual participants included in the study.

\section{References}

1. Singh L, Bansal S, Bode L, Budak C, Chi G, Kawintiranon K, et al. A first look at COVID-19 information and misinformation sharing on Twitter. ArXiv. 2020.

2. Auxier B, Anderson M. Social media use in 2021. Pew Research Center. 2021.

3. Campos-Castillo C, Laestadius LI. Racial and ethnic digital divides in posting COVID-19 content on social media among US adults: Secondary survey analysis. J Med Internet Res. 2020;22(7):e20472.

4. Fridman I, Lucas N, Henke D, Zigler CK. Association between public knowledge about COVID-19, trust in information sources, and adherence to social distancing: cross-sectional survey. JMIR Public Health Surveill. 2020;6(3):e22060.

5. Khasawneh AI, Humeidan AA, Alsulaiman JW, Bloukh S, Ramadan M, Al-Shatanawi TN, et al. Medical students and COVID-19: knowledge, attitudes, and precautionary measures. A descriptive study from Jordan. Front Public Health. 2020;8:253.

6. Berkowitz RL, Gao X, Michaels EK, Mujahid MS. Structurally vulnerable neighborhood environments and racial/ethnic COVID19 inequities. Cities \& Health; 2020.

7. CDC. COVID Data Tracker [Internet]. Cdc.gov. 2020 [cited 2021 Jul 21]. Available from: https://Covid.cdc.gov/Covid-data-tracker/

8. United States Census Bureau. QuickFacts: United States. 
9. Painter JE, Plaster AN, Tjersland DH, Jacobsen KH. Zika virus knowledge, attitudes, and vaccine interest among university students. Vaccine. 2017;35(6):960-5.

10. Ryan KA, Filipp SL, Gurka MJ, Zirulnik A, Thompson LA. Understanding influenza vaccine perspectives and hesitancy in university students to promote increased vaccine uptake. Heliyon. 2019;5(10):e02604.

11. Yang ZJ. Predicting young adults' intentions to get the H1N1 vaccine: an integrated model. J Health Commun. 2015;20(1):69-79.

12. Freimuth VS, Jamison AM, A J, Hancock GR, Quinn SC. Determinants of trust in the flu vaccine for African Americans and Whites. Soc Sci Med. 2017; 193:70-9.

13. Freimuth VS, Jamison A, Hancock G, Musa D, Hilyard K, Quinn $\mathrm{SC}$. The role of risk perception in flu vaccine behavior among African American and white adults in the United States. Risk Anal. 2017;37(11):2150-63.

14. Fry CA, Silverman EP, Miller S. Addressing pneumococcal vaccine uptake disparities among African American adults in the United States. Public Health Nurs. 2016;33(4):277-82.

15. McCormack LA, Squiers L, Frasier AM, Lynch M, Bann CM, MacDonald PDM. Gaps in knowledge about COVID-19 among US residents early in the outbreak. Public Health Rep. 2021;136(1):107-16.

16. Kecojevic A, Basch CH, Sullivan M, Davi NK. The impact of the COVID-19 epidemic on mental health of undergraduate students in New Jersey, cross-sectional study. PLoS One. 2020;15(9):e0239696.

17. Bailey SC, Serper M, Opsasnick L, Persell SD, O'Conor R, Curtis LM, et al. Changes in COVID-19 knowledge, beliefs, behaviors, and preparedness among high-risk adults from the onset to the acceleration phase of the US outbreak. J Gen Intern Med. 2020;35(11):3285-92.

18. Wolf MS, Serper M, Opsasnick L, O'Conor RM, Curtis L, Benavente JY, et al. Awareness, attitudes, and actions related to COVID-19 among adults with chronic conditions at the onset of the U.S. outbreak: a cross-sectional survey. Ann Intern Med. 2020;173(2):100-9.

19. O'Conor R, Opsasnick L, Benavente JY, Russell AM, Wismer G, Eifler M, et al. Knowledge and behaviors of adults with underlying health conditions during the onset of the COVID-19 U.S. outbreak: the Chicago COVID-19 Comorbidities survey. J Community Health. 2020;45(6):1149-57.

20. Chandler R, Guillaume D, Parker AG, Mack A, Hamilton J, Dorsey J, et al. The impact of COVID-19 among Black women: evaluating perspectives and sources of information. Ethn Health. 2021;26(1):80-93.

21. Valizadeh-Haghi S, Khazaal Y, Rahmatizadeh S. Health websites on COVID-19: are they readable and credible enough to help public self-care? J Med Libr Assoc. 2021;109(1):75-83.

22. Gerbner G, Gross L. Living with television: The violence profile. J Commun. 1976;26(2):172-99.

23. Smith K. Exploring screen time habits and the life empowerment divide at an Hbcu. Available at SSRN 3823645. 2021 Apr 10

24. Delgado R, Stefancic J. Critical race theory: an introduction. 2nd ed. New York: New York University Press; 2012.

25. Page C. Column: As COVID-19 cases grow in the African American community, so do some dangerous falsehoods. Chicago Tribune; 2020.

26. Neergaard L, Fingerhut H. AP-NORC poll: Half of Americans would get a COVID-19 vaccine [Internet]. AP NEWS. 2020. Available from: https://apnews.com/dacdc8bc428dd4df6511bfa25 9 cfec44. Accessed 2 Dec 2021

27. Cimons M. CDC says it erred in measles study. the Los Angeles times [Internet]. 1996 Jun 17 [cited 2021 Jul 21]; Available from: https://www.latimes.com/archives/la-xpm-1996-06-17-mn-15871story.html
28. Alsan M, Stanford FC, Banerjee A, Breza E, Chandrasekhar AG, Eichmeyer S, Goldsmith-Pinkham P, Ogbu-Nwobodo L, Olken BA, Torres C, Sankar A. Comparison of knowledge and information-seeking behavior after general COVID-19 public health messages and messages tailored for black and latinx communities: a randomized controlled trial. Ann Intern Med. 2021;174(4):484-92.

29. Gamble VN. Under the shadow of Tuskegee: African Americans and health care. Am J Public Health. 1997;87(11):1773-8.

30. Bajaj SS, Stanford FC. Beyond Tuskegee-Vaccine distrust and everyday racism. New England Journal of Medicine. 2021;384(5):e12.

31. Rahman K. Do vaccine mandates discriminate against Black Americans? Newsweek Global. 2021;177:34-5.

32. Almalki S. Integrating quantitative and qualitative data in mixed methods research- challenges and benefits. Journal of education and learning. 2016;5(3):288-96.

33. Guion LA, Diehl DC, McDonald D. Conducting an in-depth interview. EDIS [Internet]. 2011;2011(8). Available from: https://doi. org/10.32473/edis-fy393-2011

34. Hennink MM, Kaiser BN, Marconi VC. Code saturation versus meaning saturation: how many interviews are enough? How many interviews are enough? Qual Health Res. 2017;27(4):591-608.

35. U.S. TV consumption: average viewing time 2009-2019, by ethnicity [Internet]. Statista.com. [cited 2021 Jul 21]. Available from: https://www.statista.com/statistics/411806/average-dailytime-watching-tv-us-ethnicity/

36. Mangan D. Trump defends calling coronavirus "Chinese virus" "it's not racist at all" [Internet]. CNBC. 2020 [cited 2021 Jul 21]. Available from: https://www.cnbc.com/2020/03/18/coronaviruscriticism-trump-defends-saying-chinese-virus.html

37. Editor DKM-. Word of mouth touted as best strategy for reducing 'vaccine hesitancy' [Internet]. Washingtoninformer.com. The Washington Informer; 2021 [cited 2021 Jul 21]. Available from: https://www.washingtoninformer.com/word-of-mouth-touted-asbest-strategy-for-reducing-vaccine-hesitancy/

38. Head AJ, DeFrain E, Fister B, MacMillan M. Across the great divide: how today's college students engage with news. First Monday [Internet]. 2019;24(8). Available from: http://dx.doi. org/https://doi.org/10.5210/fm.v24i8.10166

39. Hornberger LL. Adolescent psychosocial growth and development. J Pediatr Adolesc Gynecol. 2006;19(3):243-6.

40 Arnett JJ. Emerging adulthood. A theory of development from the late teens through the twenties. Am Psychol. 2000;55(5):469-80.

41. Peralta RL. College alcohol use and the embodiment of hegemonic masculinity among European American men. Sex Roles. 2007;56(11-12):741-56.

42. Broton KM, Goldrick-Rab S. Going without: an exploration of food and housing insecurity among undergraduates. Educ Res. 2018;47(2):121-33.

43. Persoskie A, Hennessy E, Nelson WL. US consumers' understanding of nutrition labels in 2013: the importance of health literacy. Prev Chronic Dis. 2017;14:E86.

44. Willis DE, Andersen JA, Bryant-Moore K, Selig JP, Long CR, Felix HC, et al. COVID-19 vaccine hesitancy: race/ethnicity, trust, and fear. Clin Transl Sci [Internet]. 2021;(cts.13077). Available from: https://doi.org/10.1111/cts.13077

45. Anderson JL, Warren CA, Perez E, Louis RI, Phillips S, Wheeler $\mathrm{J}$, et al. Gender and ethnic differences in hand hygiene practices among college students. Am J Infect Control. 2008;36(5):361-8.

46. Williams DR, Sternthal M. Understanding racial-ethnic disparities in health: sociological contributions. J Health Soc Behav. 2010;51 Suppl(1_suppl): S15-27

47. Bowleg L. The problem with the phrase women and minorities: intersectionality-an important theoretical framework for public health. Am J Public Health. 2012;102(7):1267-73. 
48. Puar JK. I would rather be a cyborg than a goddess: Becoming Intersectional in Assemblage Theory." philoSOPHIA. 2012;2(1).

49. De Giorgio A. COVID-19 is not just a flu. Learn from Italy and act now. Travel Med Infect Dis. 2020;35(101655):101655.

50. Bolsen T, Palm R, Kingsland JT. Framing the origins of COVID19. Sci Commun. 2020;42(5):562-85.

51. Del Rio C, Malani PN. COVID-19-new insights on a rapidly changing epidemic. JAMA. 2020;323(14):1339-40.

52. Naeem SB, Bhatti R. The Covid-19 "infodemic": a new front for information professionals. Health Info Libr J. 2020;37(3):233-9.

53. Allington D, Duffy B, Wessely S, Dhavan N, Rubin J. Healthprotective behaviour, social media usage and conspiracy belief during the COVID-19 public health emergency - CORRIGENDUM. Psychol Med. 2021;1.

54. Cuello-Garcia C, Pérez-Gaxiola G, van Amelsvoort L. Social media can have an impact on how we manage and investigate the COVID-19 pandemic. J Clin Epidemiol. 2020;127:198-201.

55. Niepel C, Kranz D, Borgonovi F, Emslander V, Greiff S. The coronavirus (COVID-19) fatality risk perception of US adult residents in March and April 2020. Br J Health Psychol. 2020;25(4):883-8.

56. Dryhurst S, Schneider CR, Kerr J, Freeman ALJ, Recchia G, van der Bles AM, et al. Risk perceptions of COVID-19 around the world. J Risk Res. 2020;23(7-8):994-1006.

57. Seehuus M, Stanton AM, Handy AB, Haik AK, Gorman R, Clifton J. Impact of COVID-19 predicts perceived risk more strongly than known demographic risk factors. J Psychosom Res. 2021;140(110299):110299.

58. Latkin CA, Dayton L, Yi G, Colon B, Kong X. Mask usage, social distancing, racial, and gender correlates of COVID19 vaccine intentions among adults in the US. PLoS One. 2021;16(2):e0246970.

59. Ladson-Billings G, Tate WF. Toward a critical race theory of education. In: Critical Race Theory in Education. 2nd edition. I New York, NY: Routledge is an imprint of the Taylor \& Francis Group, an Informa Business, [2017]: Routledge; 2016. p. 10-31.

60. Spence CT, Oltmanns TF. Recruitment of African American men: overcoming challenges for an epidemiological study of personality and health. Cultur Divers Ethnic Minor Psychol. 2011;17(4):377-80.

61. Randolph S, Coakley T, Shears J. Recruiting and engaging African American men in health research. Nurse Res. 2018;26(1):8-12.

Publisher's Note Springer Nature remains neutral with regard to jurisdictional claims in published maps and institutional affiliations. 